Casos Clínicos

Arch. Esp. Urol. 2009; 62 (8): 660-663

\title{
ANEMIA Y TROMBOPENIA AISLADAS POR INFILTRACIÓN DE MÉDULA ÓSEA DE UN CARCINOMA UROTELIAL DE VEJIGA
}

Luis Miguel Herranz Fernández, Milagros Jiménez Gálvez, Pablo Garrido Abad, Carlos Suárez Fonseca, Daniel Santos Arrontes, Margarita Elices de Apellániz' y Manuel Fernández Arjona.

Servicio de Urología. Servicio de Anatomía Patológica? . Hospital del Henares. Coslada. Madrid. España.

Resumen.- OBJETIVOS: Los carcinomas uroteliales de vejiga suelen ser agresivos y pueden producir metástasis óseas que infiltren la médula ósea. La mayoría de estos casos presentan síntomas óseos y se objetivan las metástasis con pruebas de imagen. Es muy raro que pacientes asintomáticos y con un rastreo óseo normal presenten afectación medular (anemia y trombopenia) por infiltración tumoral. Lo que pretendemos es analizar esa situación a propósito de un caso.

MÉTODOS: Presentamos el caso de un varón de 41 años con un carcinoma urotelial de vejiga infiltrante que tras cistoprostatectomia radical presentó anemia y trombopenia aisladas e inexplicables que obligó a realizar una punción de médula ósea objetivándose infiltración metastásica a dicho nivel. Realizamos una búsqueda bibliográfica de casos similares.

Luís Miguel Herranz Fernández Servicio de Urología Hospital del Henares Avda. Marie Curie s/n. 28822 Coslada. Madrid (España).

luismiguel.her@terra.es

Trabajo recibido: 13 de febero 2009. 
RESULTADOS: Existen muy pocos casos de carcinoma urotelial con infiltración de la médula ósea que se manifiesten solamente por alteraciones hematológicas y tengan las pruebas de imagen normales.

CONCLUSIONES: Se debe valorar en pacientes con carcinoma infiltrante de vejiga con alteraciones hematológicas aisladas con estudio de extensión negativo realizar una punción de médula ósea para estadiar correctamente al paciente y poder ofrecer el mejor tratamiento.

Palabras clave: Carcinoma urotelial. Trombocitopenia. Anemia. Metástasis. Médula ósea. Cáncer vesical.

Summary.- OBJECTIVES: Transitional cell carcinomas (TCC) of the bladder are usually aggressive and may produce bone metastases that infiltrate the bone marrow. Most of these cases present with bone symptoms and metastases and are detected with imaging tests. It is extremely rare for asymptomatic patients with a normal bone scan to have bone marrow involvement lanaemia and thrombocytopenia) due to tumour infiltration. We aim to examine that state with a case report.

METHODS: We present the case of a 41 -year old male with infiltrating TCC of the bladder, who presented with isolated, unexplained anaemia and thrombocytopenia after radical cystoprostatectomy. A bone marrow puncture was required, in which metastatic infiltration was revealed. We performed a literature search of similar cases.

RESULTS: There are very few cases of TCC with bone marrow infiltration which become apparent only through haematological changes and have normal imaging tests.

CONCLUSIONS: Patients with infiltrating carcinoma of the bladder with isolated haematological changes and a negative extension study should be assessed by bone marrow puncture for correct staging and to be able to offer the best treatment.

Keywords: Transitional cell carcinoma. Thrombocytopenia. Anaemia. Bone marrow Metastases. Bladder cancer.

\section{INTRODUCCIÓN}

Los tumores vesicales son relativamente frecuentes y dentro de estos, los carcinomas uroteliales son los más comunes. Dichos tumores suelen ser agresivos y producen metástasis óseas en un $20 \%$ de los casos (1). Dichas lesiones óseas infiltran la médula en un $27 \%$ de los pacientes y suelen originar síntomas como dolores óseos, fracturas patológicas, etc. $(1,2)$. Además son lesiones que se suelen detectar con pruebas de imagen como radiografías; gammagrafía ósea; TAC O RMN
$(1,2)$. Es muy raro que un carcinoma urotelial de vejiga produzca alteraciones hematológicas aisladas por infiltración de la médula ósea en pacientes asintomáticos y con pruebas de imagen normales $(1,2)$. Presentamos el caso de un carcinoma de vejiga infiltrante que tras cistoprostatectomía radical presentó anemia y trombopenia aisladas e inexplicables que obligó a realizar una punción de médula ósea, encontrándose células metastásicas de carcinoma urotelial en la muestra.

\section{CASO CLÍNICO}

Varón de 41 años con antecedentes de alergia a penicilinas, hipertensión arterial en tratamiento médico y psoriasis que acude a nuestra consulta por hematuria. Se realizan citologías de orina con atipias sugestivas de malignidad y ecografía abdominal donde se visualiza una masa vesical en cara lateral izquierda de $65 \times 46 \mathrm{~mm}$ que produce una ureterohidronefrosis izquierda.

Ante estos hallazgos se somete al paciente a una RTU de vejiga resecándose una masa de aspecto infiltrante que ocupa toda la cara lateral izquierda y que no deja ver el orificio ureteral. También se coloca una nefrostomía izquierda. La anatomía patológica de dicha masa fue carcinoma urotelial indiferenciado infitrante de vejiga. Ante este cuadro se realiza un estudio de extensión con TAC toracoabdominal normal, gammagrafía ósea normal y pielografía retrógrada izquierda que objetivó una ureterohidronefrosis hasta su entrada en vejiga sin verse masa dentro de la luz ureteral.

Al ser el estudio de extensión negativo se realizó una cistoprostatectomia radical con derivación tipo Bricker. La anatomía patológica fue de carcinoma urotelial sólido de alto grado que infiltraba la grasa perivesical, próstata y uretra con bordes quirúrgicos libres de tumor (Figura 1). Se visualizan en vasos peritumorales células neoplásicas en la luz vascular (Figura 2). En cadena iliobturatriz izquierda ganglios infiltrados por carcinoma urotelial (pT4aN1MO). En el postoperatorio el paciente presenta episodios recurrentes de anemia y trombopenia que no mejoraban a pesar de transfundir hematíes y plaquetas. La función renal permaneció normal y el funcionamiento del bricker fue correcto desde el inicio. A los 5 días el paciente inicio tolerancia con éxito. Ante los cuadros aislados de anemia (en torno a $7 \mathrm{gr} / \mathrm{dl}$ de hemoglobina) y trombopenia (alrededor de 20000 plaquetas/ml) se realizó TAC abdominal donde no se objetivaron hematomas y el débito de los drenajes fue escaso desde el primer momento, descartando sangrado activo. Se retiró la enoxaparina para evitar causas farmacológicas de trombopenia. La coagulación fue siempre normal y no hubo signos de sangrado, descartándose una coagulación intravascular diseminada (CID). También se descartó un cuadro hemolítico al tener la bilirrubina normal y test de Coombs directo negativo. Al no encontrarse la causa 


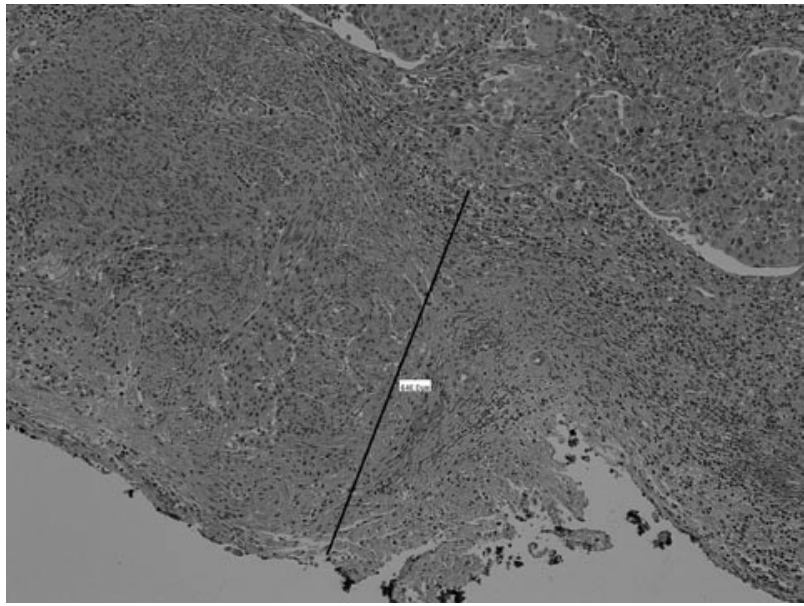

FIGURA 1. Cistectomía radical: Distancia mínima del carcinoma urotelial (esquina superior derecha) al margen quirúrgico más próximo, pintado con tinta china. HE $10 x$.

de los episodios recurrentes de anemia y trombopenia se realizó una punción-aspiración esternal de médula ósea obteniéndose células metastásicas de carcinoma urotelial (Figura 3). Al descubrir la infiltración de la médula ósea por el tumor de vejiga se realizó tratamiento hemoterápico sustitutivo y se inició tratamiento quimioterápico, falleciendo el paciente 3 semanas después.

\section{DISCUSIÓN}

El cáncer de vejiga es un tumor relativamente frecuente. En el 2004 se recogió una incidencia en la Unión Europea de 116.100 casos. Dentro de estos tumores el más habitual es el carcinoma urotelial que suele ser

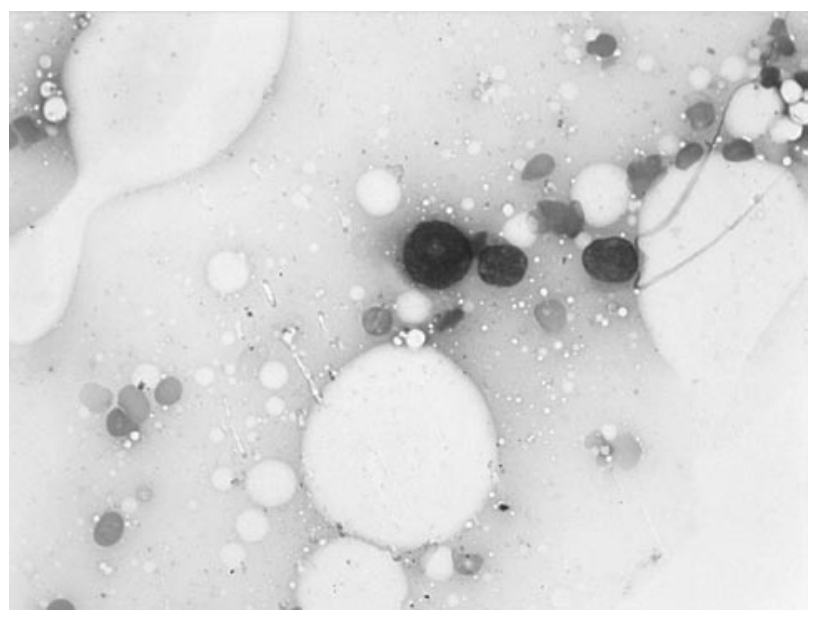

FIGURA 3. Células tumorales atípicas, correspondientes al carcinoma urotelial en aspirado de médula ósea .DQ, 100x.

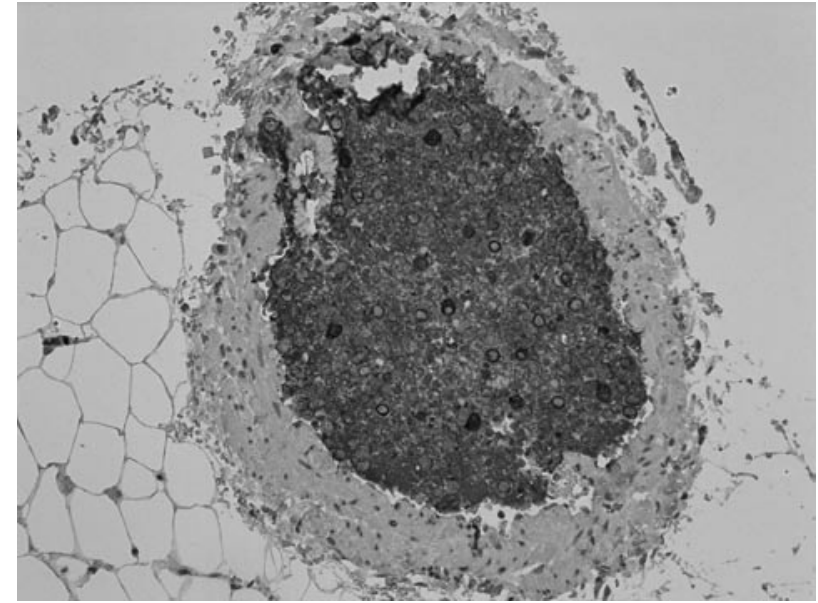

FIGURA 2. Cistectomía radical: Estructura vascular infiltrada por el carcinoma urotelial, positivo para Citiqueratinas de Amplio espectro (AE 1-AE3). IHQ, 40x.

un tumor múltiple y recurrente (3). Existen estudios que recogen en tumores de vejiga de bajo grado, una recurrencia del $50-70 \%$ en 5 años (4). Además suele ser una neoplasia agresiva siendo sus metástasis más frecuentes en ganglios linfáticos (51-88\%); hígado (13$51 \%)$; pulmones $(36-40 \%)$; huesos $(22-37 \%)$; glándulas suprarrenales $(6-21 \%)$ y cerebro $(2-6 \%)(1,2)$. Si al diagnóstico se objetiva infiltración ganglionar o metástasis a distancia presenta una supervivencia a los 5 años del $6 \%$ (4). Otra muestra de su agresividad es que existen series que tras cistectomía radical dan una supervivencia del $49 \%$ a los 5 años (4).

Cuando aparecen metástasis óseas, el pronóstico es muy malo con una media de supervivencia de 6 a 9 meses (1). Estas lesiones se producen por expansión sanguínea de las células tumorales y se manifiestan por dolores óseos, fracturas patológicas, síndrome constitucional, compresión medular, etc. $(1,2)$. Estas alteraciones óseas infiltran la médula en un $27 \%$ de los casos (1). Las pruebas de imagen que se emplean para objetivar dichas lesiones son radiografías, gammagrafía ósea, TAC y RMN $(1,2)$.

Hay muy pocos casos en la literatura de pacientes con carcinoma urotelial con infiltración de la médula ósea que se manifiesten solamente por alteraciones hematológicas. Lo extraño de estos casos es que las metástasis óseas sean asintomáticas y que no se objetiven por pruebas de imagen. En nuestra revisión, solamente hemos encontrado un caso en el que los autores refieren ser los únicos en presentar un paciente de estas características (1).

En estos casos se debe descartar la existencia de otras causas de anemia y trombopenia como sangrado activo, alteraciónes autoinmunes, interacciones farmacológicas o CID (1). 
Esta infiltración medular se maneja con tratamiento sustitutivo hemoterápico con concentrados de hematíes, plasma y plaquetas y tratamiento quimioterápico lo más precoz posible $(1,3-5)$. Es importante diagnosticar la infiltración metastásica medular para poder estadiar correctamente y dar el mejor tratamiento. Existen múltiples trabajos que intentan conseguir pruebas diagnósticas para objetivar estas metástasis medulares, sin que exista un consenso sobre cual aplicar (3-6).

\section{CONCLUSIONES}

La infiltración metastásica de la médula ósea por un carcinoma urotelial, sin síntomas óseos y con pruebas de imagen normales es una rara entidad. Es importante tener presente este caso ante pacientes con carcinoma infiltrante de vejiga con alteraciones hematológicas aisladas (sobre todo trombopenia) con estudio de extensión negativo, porque puede ser necesario realizar una punción de médula ósea para estadiar correctamente al paciente y poder ofrecer el mejor tratamiento.

\section{BIBLIOGRAFÍA Y LECTURAS RECOMENDADAS (*lectura de interés $y$ ** lectura fundamental)}

**1. Chan RC, Hundemer GL, Tatsas A, Cookson MS. Urothelial carcinoma of the bladder metastatic to bone marrow presenting as isolated thrombocytopenia. Scientific World Jour, 2007; 7: 1000-1003.

2. Kickuth R, Laufer U, Pannek J, Adamietz IA, Liermann D, Adams S. Magnetic resonance imaging of bone marrow metastasis with fluid-fluid levels from small cell neuroendocrine carcinoma of the urinary bladder. Magn Reson Imaging, 2002; 20: 691-694.

*3. Hofmann T, Buchner A, Hofstetter A, Stief CG, Oberneder R, Riesenberg R. Prognostic relevance of disseminated tumour cells in bone marrow of patients with transitional cell carcinoma. Eur J Cancer, 2007; 43: 2678-2684.

4. Güdemann CJ, Weitz J, Kienle P, Lacroix J, Wiesel MJ, Soder M, Benner A, Staehler G, Doeberitz MVK. Detection of hematogenous micrometastasis in patients with transitional cell carcinoma. J Urol, 2000; 164; 532-536.

5. Hofmann T, Riesenberg R, Buchner A, Zimmermann W, Hofstetter A, Oberneder R. Disseminated tumor cells in bone marrow of patients with transitionall cell carcinoma: inmunocytochemical detection and correlation with established prognostic indicators. $\mathrm{J}$ Urol, 2003; 169: 1303-1307.

*6. Retz M, Lehmann J, Röder C, Weichert-Jacobsen K, Loch T, Romahn E, Lühl C, Kalthoff H, Stöckle M. Cytokeratin-20 reverse-transcriptase polymerase chain reaction as a new tool for the detection of circulating tumor cells in peripheral blood and bone marrow of bladder cancer patients. Eur Urol, 2001; 39 (5): 507-515; discussion 516-517. 